\title{
The effect of employing knowledge workers from technologically advanced countries: The knowledge spillover caused by the mobility of knowledge workers in electronic industries in Asia
}

\author{
Ayano Fujiwara* \\ Senior Research Fellow, Ministry of Education, Culture, Sports, Science and Technology (MEXT), National Institute of Science and \\ Technology Policy (NISTEP), Chiyoda-ku, Tokyo 100-0013 JAPAN
}

\section{A R T I C L E I N F O \\ Article history: \\ Received: 24 May, 2017 \\ Accepted: 21 July, 2017 \\ Online: 01 August, 2017}

Keywords:

Mobility of knowledge workers

Knowledge spillover, Social

network, Tacit knowledge, Star

inventor

\begin{abstract}
A B S T R A C T
This paper is an extension of work originally presented in 2017 6th International Conference on Industrial Technology and Management (ICITM). This research focuses on the mobilization of human resources in the Asian electrical industry and analyzes the impact of engineers' international mobility on the innovation of enterprises in the host countries. I examine the characteristics of engineers who moved from Japan to China and South Korea to explore which types of engineers successful firms in China and South Korea select from rival companies in Japan. In addition, this study focuses on the role of the inventors' networks to investigate the significance of researcher mobility and knowledge spillover as mechanisms that facilitate the flow of tacit knowledge. This study reveals that during the process of innovation, informal networks play an important role in the mobility of engineers. The findings suggest that successful firms require people with analytical skills and problem-solving capacity, not "star inventors."
\end{abstract}

\section{Introduction}

To spur innovation and economic growth, the endowments of knowledge factors, such as research and development and human capital, are a necessary condition to generate new technologies. The greatest source for the generation of new economic knowledge is generally considered to be R\&D (Research and Development) [1], [2]. R\&D not only generates innovation but also develops firms' ability to identify, cultivate, and exploit knowledge and ideas developed by other firms. In other words, firms are exogenous, whereas their performance in generating technology changes is endogenous [2]. Endogenous growth models suggest that $R \& D$ activities undertaken by profit-maximizing firms represent an important investment in obtaining new knowledge, whereas knowledge is an input in the process of generating endogenous growth [3]-[5].

In this sense, knowledge spillover is an important mechanism for endogenous growth. Small and young enterprises can supplement their lack of R\&D through knowledge spillover [6]. The mechanisms by which knowledge is transmitted across firms and individuals include, for example, publications; the mobility of

${ }^{*}$ Corresponding Author: Ayano Fujiwara, Science and Technology (MEXT), National Institute of Science and Technology Policy (NISTEP), Chiyoda-ku, Tokyo 100-0013 JAPAN | Email: ayanokaayano@gmail.com employees, scientists and engineers; and reverse engineering. The mobility of knowledge workers in general and new firm start-ups in particular has become an important mechanism of knowledge spillover [7]. Michelacci (2003) implies that a low rate of return on R\&D may be attributable to an inability to transform new knowledge into economic opportunities through skills, aptitudes, and insights [8].

Knowledge that can be easily codified can be transmitted and understood over long distances at very low cost [9]. However, tacit knowledge is difficult to communicate, and it therefore relies on face-to-face interaction to be transmitted effectively [10]. Thus, the knowledge spillover resulting from the mobility of knowledge workers is especially important because it facilitates the transfer of tacit knowledge, which is not readily transferable via codified sources. The mobility of knowledge workers, such as scientists, inventors, and engineers, has a significant and positive impact on new firms' output and productivity growth [11], [12]. Knowledge workers from large, established firms may have knowledge and ideas about inventions and ultimately about innovations. The mobility of knowledge workers therefore plays a central role in the spillover of knowledge and ultimately in economic growth. Additionally, informal networks and labor mobility are closely linked with respect to their emergence and re-configuration [13]. Cross et al. (2001) investigate methods of improving employees' 
ability to create and share knowledge in social networks [14]. However, the literature identifying the mechanisms underlying the transmission of knowledge spillover by social networks remains underdeveloped.

Engineers' mobility plays an important role in the transfer of knowledge from stable and mature enterprises to high growth and young enterprises, especially in high-technology sectors. Many studies have examined the relationship between the mobility of knowledge workers and innovation; however, the relationship between the characteristics of engineers who move abroad and innovation is a less-researched field. Only a few studies have analyzed the impact of R\&D investment and human capital on innovation. Therefore, this study empirically analyzes the impact on innovation of the quality of the talent that migrated from developed countries.

This paper focuses on the link between the mobility of individual engineers and knowledge spillover. The purpose of this study is to identify the influence of engineers' mobility on firm development and innovation. I investigate the role of engineers who migrated from large, established companies to young companies in transmitting knowledge. Engineers from large, established corporations often have new knowledge that they acquired through research and development work in their firms' labs.

I propose a hypothesis to investigate the link between researchers' mobility and R\&D performance. The hypothesis is that young, successful firms in China and South Korea are selective in their hiring, overwhelmingly recruiting talent from large, established firms in countries such as Japan with the expectation that the knowledge spillover embedded in their new hires will allow the young firms to catch up technologically. I explore this hypothesis by investigating patent data to estimate the effect of knowledge transfers from Japanese firms to Chinese and South Korean firms. I analyze the mobility of engineers from Japanese firms to Chinese and South Korean firms by drawing on patent data from 1976 to 2013. Young, successful firms in China and South Korea employ many engineers who were formerly employed by Japanese firms. I therefore examine the characteristics of engineers who moved from Japan to China and South Korea to explore what types of engineers Chinese and South Korean firms select from rival companies in Japan. In addition, this study focuses on the role of engineers' networks to investigate the significance of engineer mobility and knowledge spillovers as mechanisms facilitating the flow of tacit knowledge. Thus, I use social network indices to analyze co-invention networks. Additionally, I examine whether these engineers play an essential role in innovation within their new companies.

Next, I examine what types of researchers absorbed technology and knowledge from developed companies and contributed to innovation in young companies such as Chinese and South Korean firms. To this end, I use a knowledge production function model to obtain insights into the process of innovation using the knowledge embedded in new hires. For the specific methods of analysis, the knowledge production function developed by Pakes and Griliches (1984) is used; for the explained variables, patent citation counts are used as a representative index to measure innovation through the number and quality of patents [15]. I use panel data from 5 young, successful firms in China and South Korea over the past two decades.
A few studies have focused on the effect of talent migration on knowledge spillover via informal networks. One of these papers focuses on scientific labor as a measure of spillover [16] and studies the personal characteristics of scientists employed at a biotech company. Here, I extend this framework by examining engineers who moved from developed firms in Japan as the source of knowledge transmission. This study examines the relationship between the characteristics of individual knowledge workers and knowledge spillovers. It also investigates the relations between the mobility of knowledge workers and their informal networks during the process of innovation.

\section{Theory and Hypotheses}

\subsection{Mobility of knowledge workers and innovation}

This study conducted an empirical analysis of the effect of knowledge workers' mobility on innovation. In the previous literature, the influence of investment in R\&D and human capital has been analyzed [15], [17]-[22]. These studies examine the influence of R\&D input on R\&D output by using the knowledge production function and considering the patent productivity of R\&D using company-level data from North America and Europe. In addition, several models related to innovation have been presented, including some that use a knowledge-production function to analyze the effect on innovation activities produced by human capital and investment in R\&D. Those studies focus on the role of human capital and R\&D expenditures in obtaining knowledge capital in return.

Unlike those previous analyses of innovation and technological change that focus on the firm, in this paper, I focus on the individual. Some researchers have examined scientist mobility in the context of individual careers. Many of these studies focus on Ph.D. graduates [23], [24]. Zucker et al. (1997) examine the mobility of "star scientists" as a knowledge transfer mechanism [25].

The most prevalent model in the literature on innovation is that of the knowledge production function, which was formalized by Zvi Griliches (1979) [19]. The inputs in the model of the knowledge production function are $R \& D$ cost, human capital, skilled labor, and educational levels [19], [26]. The model of the knowledge production function from the literature on innovation and technological change can be represented as

$$
\mathrm{IA}_{i}=\alpha \mathrm{RD}_{i}^{\beta} \mathrm{X}_{i}^{\gamma} \varepsilon_{i}
$$

In the equation, IA represents the degree of innovative activity, $R D$ represents $R \& D$ input, and $X$ represents human capital inputs.

Conventionally, R\&D investment costs have been widely used as surrogate variables for innovation. However, the size of $R \& D$ costs is an input index, which cannot be used to measure the output of innovation. In this study, I use the number of patents as an output index of innovation. However, both the quality of patents and the number of patents are important issues. In this regard, patent quality has been studied, and the number of times a patent has been cited has been proposed as a proxy for patent quality. Trajtenberg (1990), Jaffe et al. (2000), Reitzig (2003), Hall et al. (2005) and Carpenter et al. (1981) have found a strong correlation between the number of citations and the quality of patents [27]-[30]. For example, Harhoff et al. analyze American and German patents and find that the number of citations in the patents that were updated before expiration was greater than that for the patents that expired 
earlier [31]. For these reasons, I use the number of citations as an index to measure innovation in this study.

\subsection{The characteristics of engineers hired by successful firms in China and South Korea}

A combination of various types of technologies can be interpreted as an indicator of the increasingly complex nature of innovation [32]. Small enterprises can make up for a lack of innovation through knowledge spillovers from engineers who have experience with the complex nature of an innovation. This study analyzes the impact of the transfer of technology and knowledge on innovation in a corporation caused by the mobility of engineers who previously held positions with mature enterprises and then moved to young, successful firms. For this analysis, the characteristics of the knowledge workers hired by young, successful firms in emerging nations must first be analyzed. In particular, I shed light on the link between engineers' personal characteristics and inventors' attraction to a rapidly growing company. To measure the characteristics of talent, various indices have been considered. From the recruitment perspective, superiority as a researcher and whether the person held a position where in-house technology and knowledge could be accumulated are important factors.

Young, successful firms in China and South Korea must be selective in their hiring when recruiting engineers from Japanese firms. Warren (1997) emphasizes that a person who has produced results in his or her former work will have a positive influence on the new firm's productivity after migration [33]. Thus, successful firms will select engineers who have had excellent results in their former job. A high value for the number of citations received (forward citation) implies that a technology is used in diverse fields of future invention. I hypothesize that successful firms will hire inventors whose patents have been extensively cited. A high score on the number of patents cited (backward citation) means that the patents are based on past inventions drawn from diverse categories. This leads to my first hypothesis:

Hypothesis 1-1. Successful firms employ new hires who have had excellent results in their former jobs and have experience with the complex nature of innovation.

Because recruited talent is expected to lead local inventors in developing technology and knowledge in emerging nations' corporations, their rich experience and knowledge should have a strong impact. Therefore, successful firms will hire engineers who have long-term experience in stable and mature enterprises. Additionally, successful firms will hire engineers who have rich experience in a variety of technical domains. Thus, I propose as follows:

Hypothesis 1-2. Young, successful firms select engineers as new hires who have long-term experience.

Hypothesis 1-3. Young, successful firms select engineers as new hires who have rich experience in a variety of technical domains.

Similar statements can be made about informal networks. Successful firms employ people who occupy central positions in inventor networks. In other words, "star engineers" are selected by Chinese and South Korean companies. Zucker et al. (1996) study the mobility of "star scientists". They emphasize that the very best "star scientists" play central roles in both the development of the science and its successful commercialization [34]. Hence, I propose as follows: hires.

Hypothesis 1-4. Successful firms select "star inventors" as new

Zellner (2003) studies the various elements of knowledge transfer via scientists' migration [35]. He investigates the migration of scientists formerly employed at the Max Planck Society in Germany by using survey data obtained from a sample of scientists who moved from the Max Planck Society into the commercial sector. The main result of this analysis is that knowledge that is specifically related to a certain research question is not the most important issue for the scientists employed by the Max Planck Society who transferred into the private sector. The results suggest that non-specific knowledge was valued more highly than specific knowledge. In other words, broad knowledge and analytical skills are more important than propositional knowledge. It is said that those who are strongly tied to the star people in the network can acquire a wide range of knowledge [36]. Hence, I propose as follows:

Hypothesis 1-5. Successful firms select engineers as new hires who are strongly connected to "star engineers."

\subsection{The type of talent contributes to innovation in emerging nations' enterprises}

Knowledge workers who have rich experience with inventions will contribute to innovation. Amalya (2004) indicates that scientists who have rich experience with inventions increase the number and citation rate for firm patents and contribute to firms' success [37]. Another study [25] finds that "star" bio-scientists play a central role in their firms' success. Thus, knowledge workers from developed countries are expected to have vast scientific knowledge and communicative competence. This discussion leads to the following hypothesis:

Hypothesis 2-1. "Star engineers" who were formerly employed in a developed country's enterprises contribute to innovations by emerging nations' enterprises.

The ability to exploit external knowledge is a critical component of innovative capabilities, and the ability to evaluate and utilize outside knowledge is related to the level of prior knowledge. The ability to recognize the value of new information, assimilate it, and apply it to innovation is defined as "absorptive capacity" [1]. An inventor must have a strong absorptive capacity or the ability to successfully replicate new knowledge to access the new knowledge developed by other units [38]. A similar statement can be made about firms' absorptive capacity. While encompassing a firm's ability to imitate new process or product innovations, absorptive capacity can also include a firm's ability to exploit outside knowledge. Cohen (1990) suggests that the development of a firm's absorptive capacity will build on its prior investment in $R \& D$ [1]. Thus, I hypothesize that engineers who moved from Japanese firms will contribute more to Chinese and South Korean firms' innovation in the growth stage. Hence, I propose as follows:

Hypothesis 2-2. To promote innovation through knowledge spillover, enterprises in emerging nations need an adequate "absorptive capacity." 


\section{Data and Methodology}

\subsection{Data}

In this study, I examine the characteristics of engineers who moved from Japan to China and South Korea and the characteristics of engineers who contribute to Chinese and South Korean firms' innovation. I used US patent data for filings by Japanese, Chinese and South Korean companies between 1976 and 2013. I calculated the number of years of experience from the year that the inventor first filed for a patent, so it was necessary to use data from as far back as 1976. It is said that a particularly high number of engineers who moved from Japanese companies to Chinese and South Korean companies are in the electrical equipment industries. Therefore, I used patents from the $\mathrm{H}$ section of the IPC classes. IPC stands for International Patent Classification and is a universal patent classification that was created based on the "Strasbourg Agreement on International Patent Classification" (effective in 1975). The H section indicates a patent in the electric field. I targeted approximately 270,000 patents from Japanese electrical manufacturers, approximately 50,000 Chinese patents, approximately 70,000 South Korean patents, and approximately 50,000 Taiwanese patents. I extracted all of the inventor names from those patents and confirmed people with the same name as Japanese inventors among the Chinese and South Korean inventors. Because inventors with identical names as inventors in Section $\mathrm{H}$ are highly likely to be the same people, the fact that their names appear on patents filed by both Japanese companies and Chinese and South Korean companies means that these people have moved between these companies. However, it cannot be denied that it is possible that the same name might refer to different people. Therefore, I decided to establish a criterion for the degree of similarity between IPC numbers at the IPC main group level, and only in cases in which that criterion was met did I judge the people to be equivalent. In this way, I judged the names of inventors who appeared in both Japanese and Chinese or South Korean patents to be equivalent when they met the requirements for a connection between IPC numbers, and I judged them to have moved between Japanese companies and foreign companies, thus raising the probability that these were actual movements. After identifying the movements of all of the inventors, I judged whether they moved from or to a Japanese company. Moreover, using the last patent application by their former company and the first patent application by their destination company, I calculated the probability of the timing of the movement for all transferees. I checked the patent data for the names of the companies where the inventors previously worked in Japan and the names of the companies to which they moved in China and Korea. I deleted data that conflicted with the period in which they were assigned to one of the countries.

Then, I calculated a network index for all of the inventors that were employed by Japanese companies to check the characteristics of the inventors who were also employed by Chinese or South Korean companies.

I focused on 5 successful companies in China and South Korea: Samsung, LG, Hyundai, Huawei and Hon Hai Precision. Samsung, LG, and Hyundai are South Korean companies. Huawei is a Chinese company. Hon Hai Precision is Taiwanese company.

For Hypothesis 1, the analysis is based on the notion that rapidly growing companies are selectively recruiting engineers from developed countries. The engineers who migrated from corporations in Japan to the 5 successful companies and to other companies in China and South Korea were identified from the patent data filed by the Japanese companies. All of the engineers' names listed as inventors on the patents mentioned above are extracted. Excluding those with identical names, there are approximately 170,000 inventors from Japanese companies and approximately 50,000 inventors from Chinese and South Korean companies. Then, all of the names of the inventors mentioned above who appear in both patents filed by Japanese companies and those filed by non-Japanese companies are extracted. Because engineers with identical names who are mentioned as inventors in Section $\mathrm{H}$ are highly likely to be the same people, the fact that their names appear on patents filed by both Japanese companies and Chinese and South Korean companies means that these people have worked in both countries. However, even given identical names, some of the data may refer to different engineers. Therefore, certain conditions were set to eliminate these cases by checking the International Patent Classifications. Next, with regard to patents with inventor names that match those extracted as above, the company that employed them was identified by examining the applications. Then, by considering the order of the years in which the applications were filed, the researchers' career changes could be identified regarding the company they left and the company they then joined.

In Hypothesis 2, to analyze how talent from developed countries contributes to innovation by emerging nations' enterprises, patent data and financial data from a 22 -year period (1990-2011) are used to perform an analysis using panel data for a Chinese corporation (Huawei), a Taiwanese corporation (Hon Hai), and three South Korean companies (Samsung, LG, and Hyundai).

\subsection{Explained variable}

Regarding Hypothesis 1, to indicate which type of knowledge workers migrate to emerging nations' enterprises, the explained variable can have two values: 1 for migrating to emerging nations' enterprises and 0 for not migrating.

For Hypothesis 2, the number of patents is used in this study to determine innovations by emerging nations' enterprises when measuring the results for knowledge workers from developed countries' corporations. Other well-known studies have used the knowledge-production function approach [15], [17]-[22]. Thus, the knowledge production function employing the number of patents is used in this study.

Furthermore, from the perspective of measuring the quality of patents, the citation count is also used as an explained variable because the analysis shows that in many cases, the citation count of American patents (forward citation) is strongly correlated with the value of the patent [27]-[30]. For example, Hall et al. (2005) demonstrate that the aggregation of the citation count of a patent owned by a corporation is correlated with the company's share price [30]. In this way, the citation count is an excellent index to verify the impact of the quality of patents.

\subsection{Explanatory variable}

In this study, to analyze the impact caused by the mobility of human resources and inventor networks on innovation by Chinese and South Korean firms, numerous indices representing the quality of talent are established. To analyze the role played by the mobility of knowledge workers and their influences on innovation and growth in Chinese and South Korean companies, I examine the 
characteristics of knowledge workers based on the aspects of skills and inventor networks. Specifically, a social network index and some indices to measure the features of the talent are used as explanatory variables based on patent data.

I use social network indices of co-invention by inventor networks using patent data. I calculate the social network indices for each inventor in the company that employs him or her, and I examine the structural positions in the network. Social networks are composed of different nodes of individuals and the social relationships that individually connect them. By observing the centrality index of each node, it is possible to analyze the characteristics and roles of each node in the overall network. I investigate co-inventor networks by using patent data and develop social network indices based on degree centrality, closeness centrality, betweenness centrality (Freeman, 1979), eigenvector centrality (Bonacich, 1972), clustering coefficients, and page ranks. Degree, betweenness, closeness, and eigenvectors are the four main measures of centrality. These centrality measures capture the relative position of an individual within the network. Degree centrality is defined as the number of links incident upon a node - in other words, the number of ties that a node has [40]. Degree centrality is based on a measured focus on the level of communication activity. In contrast, betweenness centrality reflects the intermediary location of a node along the indirect relationships linking other nodes [40]. Betweenness centrality captures stress control and the capacity to interrupt communication. The maximum theoretical value of betweenness centrality is given by $(n-1)(n-2) / 2$ [41]. Closeness centrality measures depend on the geodesic distance, which is the minimal length of an indirect path. Freeman (1979) suggests that measures of centrality based on closeness reflect a node's freedom from the controlling actions of others and their capacity for independent action within the network [40], [42]. Eigenvector centrality reflects the fact that individuals might profit from well-connected friends [43]. I focus on degree centrality and eigenvector centrality.

A node with high degree centrality has many direct connections with other nodes, and people with high degree centricity are central people in communication within the network. [44]. High degree centrality means that the inventor has experience cooperating with many other inventors from his company. As an individual becomes exposed to increased degree centrality, his or her position in the network will attain a higher status [45], providing more opportunity to learn, acquire and utilize knowledge. Thus, an inventor who has high degree centrality is considered a "star inventor."

Eigenvector centrality is a centrality index proposed by Phillip Bonacich; it evaluates not only high-scoring nodes but also all nodes that are connected to high-scoring nodes. In other words, a high score for eigenvector centrality means that the node has connections with high-scoring nodes. This means that eigenvector centrality is a measure of the influence of a node in a network. Being related to a node that has many relationships with other nodes implies an important position within the network. In other words, an inventor who has a high score on eigenvector centrality is a person with whom "star inventors" always want to work. This is because individuals in such positions can obtain a great deal of important information and have both analytical skills and problemsolving capacity. Recently, the strategic importance of patent analysis has been highlighted by high-technology management as the process of innovation has become more complex [46]. Furthermore, patents facilitate analytical work through their relative advantages [48]. In addition, to measure the features of migrating talent, variables such as the number of migrated inventors, the size of the company of origin, the number of years in the inventor's career, the citation count, the forward citation count, the Herfindahl-Hirschman Index of the IPC number, and eigenvector centrality are used.

The patent citation count is used as a representative index to indicate patent quality. This approach has been validated by various studies [49], [31], indicating that the forward citation count is effective for measuring the quality of a patent. In addition, an inventor who has been involved with many high-quality patents can be regarded as excellent. The total citation count of a patent in which the inventor in question has been involved is used as a surrogate index for his/her excellence. Thus, the forward citation number is an important performance indicator to measure the performance of individual inventors. I therefore count all forward citations received by each patent for each inventor.

Furthermore, as an index to measure patent quality, in addition to the citation count, it has been noted that the number of a patent's backward citations correlates with the quality of the patent [31]. The number of backward citations is effective for measuring a patient's originality [50]. A high score on the number of backward citations means that the patent is complex, and a low score means that the patent is highly original. Therefore, the number of times a patent has been cited has been added as a variable to measure the quality of talent. I use the total number of patent citations (backward citations) as a representative index of originality and complexity.

The number of years in the inventor's career is calculated as the number of years elapsed since the year in which the inventor in question filed his/her first patent application.

In addition, the Herfindahl-Hirschman Index of the IPC number can measure whether an inventor has been involved with patents in a specific technical domain or in a variety of technical domains. In other words, a high HHI value indicates that the inventor specializes in a specific technical field, whereas a low $\mathrm{HHI}$ value indicates that the inventor has wide knowledge covering a variety of technical fields.

Another factor affecting the quality and quantity of patents is an increase in R\&D costs. There have been numerous analyses [15], [17], [18], [21] of the cost of R\&D and patent applications. In general, the number of patents increases and their quality improves as $\mathrm{R} \& \mathrm{D}$ cost increases, regardless of inventor quality. Therefore, in this study, R\&D cost in the current period is also used as a variable.

\subsection{Control Variables}

Most empirical studies of firm performance include firm size as either a control variable or an independent variable. Following this tradition, I use firm size as a control variable. In terms of the scale of the company of origin, corporations with $\$ 100$ trillion or greater in sales are classified as large, whereas corporations with less than $\$ 100$ trillion in sales are classified as small.

\subsection{Estimation technique}

To test the first hypothesis and determine the characteristics of knowledge workers migrating to Chinese and South Korean enterprises from Japanese corporations, a logistic model is built for 
the analysis using two-value objective variables. The model formula is as follows:

$$
\begin{aligned}
& \mathrm{Pi}(\mathrm{i}=1)=\mathrm{F}\left(\mathrm{C}+\sum \text { a ixi }\right) \\
& \mathrm{Pi}=\exp \left(\mathrm{C}+\sum \text { a ixi }\right) /\left(1+\exp \left(\mathrm{C}+\sum \text { a ixi }\right)\right)
\end{aligned}
$$

Pi represents the probability of mobility of engineer $i$, taking the value of 1 if the inventor migrated to an emerging nation and the value of 0 if he/she did not. $\mathrm{F}$ is the cumulative distribution function, $\alpha \mathrm{i}$ is a coefficient, $\mathrm{Xi}$ is an explanatory variable, and $\mathrm{C}$ is a constant.

To test the second hypothesis and determine the influence of engineer mobility on innovation by Chinese and South Korean firms, the knowledge production function developed by Griliches and Regev (1995) is applied [26]. The knowledge production function measures the effectiveness of $R \& D$ investment for increasing knowledge. Griliches and Regev (1995) establish the following formula to compare labor productivity between companies [26].

$$
\mathrm{Y}=\mathrm{Xb}+\mathrm{Zc}+\operatorname{lm}+\mu
$$

Here, $\mathrm{Y}$ represents the logarithm of productivity, $\mathrm{X}$ is the logarithm of the input variable (intermediate inputs and capital services per person), and $\mathrm{Z}$ represents the control variables (e.g., dummy variables for size, age, and location). The authors establish eight variables: 1) intermediate inputs and fixed capital services, 2) R\&D capital and labor quality (as a proxy for human capital), 3) size, 4) sector and type of ownership, 5) industry grouping, 6) establishment year, 7) mobility status (entry and withdrawal status), and 8) year dummies.

In this study, the impact of the migration of engineers from corporations in developed countries on innovation in emerging nations' enterprises is examined by entering the variable related to the knowledge worker's characteristics. Here, I extend this framework to examine the link between knowledge workers' characteristics and innovation. The model formula is as follows.

$$
\mathrm{Y}=\mathrm{Xb}+\mathrm{Zc}+\mathrm{Wd}+\mathrm{lm}+\mu
$$

$\mathrm{Y}$ stands for the degree of innovative activity, $\mathrm{X}$ represents R\&D inputs, $\mathrm{Z}$ represents local human capital inputs, and $\mathrm{W}$ represents the characteristics of knowledge workers who migrated from Japan.

In this study, I use the number of patents and the number of citations as a surrogate variable for innovative activity. The number of patents used as an explained variable represents nonnegative numeric data. In this study, a fixed-effect model and a random-effect model are used to perform the calculations, following the example of Hausman et al. (1984) [17]. Hall and Mairesse (1995), Mairesse and Hall (1996), and Harhoff (1998) analyze French, American, and German manufacturers using a fixed-effect model to control for the deviation of a company's fixed effect [51]-[53].

\section{Results and discussion}

After the text edit has been completed, the paper is ready for the template. Duplicate the template file by using the Save As command, and use the naming convention prescribed by your conference for the name of your paper. In this newly created file, highlight all of the contents and import your prepared text file. You are now ready to style your paper; use the scroll down window on the left of the MS Word Formatting toolbar.

\subsection{Identify the Headings}

The main regression results are reported in Table 1. I analyze the characteristics of knowledge workers recruited as new hires by 5 successful firms in China and South Korea. A logistic regression model is used to verify the influence of the basic explanatory variables, such as inventors' individual social network index, the number of years in their career, and the evaluation of their invention. Model 1-6 reports the results for South Korean companies and Model 7-10 reports the results for Chinese companies.

Consistent with Hypothesis 1-1, the results indicate that the coefficient of forward citations is significantly high for South Korean companies; however, it is negative for Chinese companies. Conversely, the results for the number of backward citations are negative for South Korean companies and positive for Chinese companies. These results mean that South Korean firms employ knowledge workers who have had excellent results in their former jobs and have the ability to be original. In contrast, Chinese firms employ knowledge workers who have not had excellent results in their former jobs but who have experience with the complex nature of innovation. These results suggest that there is a high probability that South Korean companies select new talent by considering the number of times that a given patent has been cited, which is the most commonly used index to indicate a patent's importance.

In addition, consistent with Hypothesis 1-2, the variable for years of experience is negative in Model 5 (Hyundai) and Model 7 (Huawei) and positive in Model 1 (Samsung), Model 3 (LG), and Model 9 (Hon Hai).

The coefficient of HHI is negative for all of the companies. This result means that successful firms in China and South Korea select engineers who have experience not in a specified technical domain but in a variety of technical domains with Japanese firms. This result supports Hypothesis 1-3.

Consistent with Hypothesis 1-4, the coefficient for degree centrality is statistically positive in Model 3 and statistically negative in Model 7. Inventors who have high degree centrality tend to have experience cooperating with many other inventors in their company. I define them as "star inventors." This result suggests that LG acquires "star inventors" and Huawei does not. In other words, the specific knowledge that an inventor absorbed while employed at a mature enterprise is not necessarily the most important element transferred into emerging nations' companies.

However, consistent with Hypothesis 1-5, the results show that the coefficient for eigenvector centrality is significantly positive in Model 2, Model 4, and Model 10. This result means that Chinese and South Korean companies prefer talent with high eigenvector centrality. Inventors who have a high score on eigenvector centrality are inventors with whom the "star inventors" always want to work. In other words, young, successful firms acquire knowledge workers who connect strongly with the "star inventors." This result supports Hypothesis 1-5.

Table 2 shows the results analyzing the link between the quality of human capital inputs and innovation using a fixed- effect model and a random-effect model. Model 1-4 reports the results for 1990-2011. The null hypothesis can be dismissed based on the Hausman test regarding the selection of the two calculation methods. Therefore, the fixed-effect model is preferable. 
Consistent with Hypothesis 2-1, regarding knowledge workers employed by Japanese firms, the coefficient for eigenvector centrality is positive in Model 1 and Model 3 in Table 3. Additionally, the coefficient for degree centrality is positive in Model 1 and Model 3. However, only the coefficient for eigenvector centrality in Model 1 is positive. The results showing a positive coefficient for eigenvector centrality mean that inventors who strongly connect with "star inventors" contribute to innovation in emerging nations' companies. In other words, the inventors who connect strongly with "star inventors" contribute more to young companies' innovation as measured by the number of patents than do "star inventors" who were formerly employed by mature companies. Thus, Hypothesis 2-1 is not supported.

Table 3 shows the results of analyzing the link between the quality of human capital inputs and innovation using a fixed effects model and a random effect model. Model 5-8 reports the results for 2001-2011. The null hypothesis can be dismissed based on the Hausman test regarding the selection of the two calculation methods. As a result, the fixed-effect model is preferable.

Consistent with Hypothesis 2-2, the coefficient for the number of Japanese inventors is statistically positive in Model 5. This result shows the impact on innovation by emerging nations' enterprises as measured by the number of patents won by Japanese researchers employed at these companies from 2001-2011. Similarly, the coefficient for the number of Japanese inventors is statistically positive in Model 1. However, the level of statistical significance is different. The coefficient for the number of Japanese inventors in Model 5 is significant at the 5\% level; however, the coefficient for the number of Japanese inventors in Model 1 is significant at the $10 \%$ level. These results mean that inventors with experience in a developed country contributed more to quantity of innovation after 2001 than in the period from 19902001. This tendency is not similar in quality of innovation (see Model 3 and Model 7). The results suggest that after emerging nations' enterprises strengthened their "absorptive capacity," there was a high possibility that new hires who had formerly been employed in developed countries would contribute to innovation, as measured by the quality of patents. Thus, Hypothesis 2-1 is partially supported.

\section{Conclusion}

In this study, I identify the influence of engineers' mobility on firms' development and innovation. In particular, this study focuses on knowledge spillover and transnational networks between companies in developing and developed countries from the perspective of inter-organizational labor mobility. I investigate the role of engineers who migrated from Japan to China and South Korea in transmitting knowledge from large, established companies to young companies.

This analysis has yielded important insights into how knowledge workers' characteristics condition their transnational mobility and engagement in international knowledge development. First, this analysis of the characteristics of inventors who migrate from Japanese corporations to China and South Korea indicates that rapid growth companies recruit knowledge workers from Japanese companies based on differences in priority characteristics such as skills, the length of their careers, and their experience in technical fields. Interestingly, top firms, such as Samsung and LG, are more selective in their hiring than other firms in that they overwhelmingly recruit talent from Japan. Successful companies in China and South Korea select engineers who do not have experience cooperating with many other inventors but who do have analytical skills and problem-solving capacity. In other words, successful firms require people with analytical skills and problem-solving capacity, not "star inventors." This result means that for successful companies, non-specific knowledge is more important than specific knowledge. These findings dovetail reasonably well with the findings from Zellner's study (2003) [35].

Second, the knowledge production function is applied to analyze what types of knowledge workers contribute to innovation in emerging nations using panel data. With respect to innovation, inventors who connect strongly with "star inventors" from developed companies play an important role, as do the "star inventors" themselves.

Based on the above results, it can be argued that at the time of hiring, it is most important to select people with the applicable skills, which suggests that corporate growth requires not only "star inventors" but also inventors who connect strongly with the "star inventors."

My study has notable limitations. At this time, only analyses of Chinese and South Korean enterprises were conducted. However, in terms of the relationship between innovation and talent migration, it would be worthwhile to expand the scope of analysis to all emerging nations. Additionally, this research focused on the electronics industry. However, the effect of inventor mobility may differ considerably from industry to industry. Therefore, further research is needed on other industrial sectors.

Nevertheless, the theoretical framework developed and applied herein draws on a broad range of academic literature. The empirical findings are well aligned with the framework regarding the link between the mobility of knowledge workers and knowledge spillover. The approach developed herein will hopefully inspire future empirical studies to analyze the role of migrating knowledge workers.

\section{Conflict of Interest}

The author declare no conflict of interest.

\section{Acknowledgment}

This research was supported by JSPS KAKENHI, Grant Number JP16K13383. This work was supported by the National Institutes of Science and Technology Policy. In particular, I am grateful to Prof. Toshiya Watanabe (The University of Tokyo) who provided many suggestions and comments on a previous version of this paper. 


\section{References}

[1] Cohen, Wesley, Levinthal, Daniel, Absorptive Capacity: A New Perspective on Learning and Innovation. Administrative Science Quarterly, Vol. 35 Issue 1, 128-152. 1990.

[2] Cohen, W. M., \& Levinthal, D. A.. Innovation and learning: the two faces of R \& D. The economic journal, 99(397), 569-596. 1989.

[3] Romer, Paul M., Endogenous Technological Change: The Journal of Political Economy, Vol. 98, No. 5, 71-102. 1990.

[4] Segerstrom, Paul S, Anant, T C A, Dinopoulos, EliasA, 1990. Schumpeterian Model of the Product Life Cycle: The American Economic Review,80, 10771091.

[5] Zoltan J. Acs, Pontus Braunerhjelm, David B. Audretsch, Bo Carlsson, 2009. The knowledge spillover theory of entrepreneurship: Small Business Economics, 15-30.

[6] Audretsch, David B., and Erik E. Lehmann. "Does the knowledge spillover theory of entrepreneurship hold for regions?." Research Policy 34.8: 11911202.2005.

[7] Audretsch, David, Dirk Dohse, and Annekatrin Niebuhr. "Cultural diversity and entrepreneurship: a regional analysis for Germany." The Annals of Regional Science 45.1: 55-85. 2010.

[8] Michelacci, Claudio. "Low returns in R\&D due to the lack of entrepreneurial skills." The Economic Journal 113.484: 207-225.2003.

[9] Donald Patton, Martin Kenney, The spatial configuration of the entrepreneurial support network for the semiconductor industry: R\&D Management, Vol. 35 Issue 1, 1-16. 2005.

[10] Feldman, M.P. Location and innovation: the new economic geography of innovation, spillovers, and agglomeration: The Oxford Handbook of Economic Geography, 373-394. 2000.

[11] Romer, Paul M., 1990. Endogenous Technological Change: The Journal of Political Economy, Vol. 98, No. 5, 71-102.

[12] Grossman, Gene M., and Elhanan Helpman. Protection for sale. No. w4149. National Bureau of Economic Research, 1992.

[13] Zellner, Christian, and Dirk Fornahl. "Scientific knowledge and implications for its diffusion." Journal of Knowledge Management 6.2: 190-198.2002.

[14] Cross, Rob, Parker, Andrew, Prusak, Laurence, and Borgatti, Stephen, Knowing What We Know: Supporting Knowledge Creation and Sharing in Social Networks, Organizational Dynamics, Vol. 30 Issue 2, 100-120. 2001.

[15] Pakes, Ariel and Zvi Griliches, Estimating distributed lags in short panels with an application to the specification of depreciation patterns and capital stock constructs: Review of Economic Studies 51(2), 243-262. 1984.

[16] Audretsch, David B., and Paula E. Stephan. "Company-scientist locational links: The case of biotechnology." The American Economic Review 86.3: 641-652. 1996.

[17] Hausman, Jerry, Bronwyn Hall, and Zvi Griliches, Econometric models for count data with an application to the patents R\&D relationship: Econometrica 52, 909-938. 1984.

[18] Hall, Bronwyn, Avi Griliches, and Jerry Hausman. Patents and R\&D: Is there a lag?: International Economic Review 27, 265-83. 1986.

[19] Griliches, Zvi,, 1990. Patent statistics as economic indicators: A Survey: Journal of Economic Literature, 28, 1661-1797.

[20] Kortum, Samuel and Josh Lerner, Stronger protection or technological revolution: what is behind the recent surge in patenting?: CarnegieRochester Conference Series on Public Policy, 48, 247-304. 1998.

[21] Crépon, B, E. Duguet and Jacques Mairesse, Research and development, innovation and productivity: an econometric analysis at the firm level: Economics of Innovation and New Technology. 1998.

[22] Hall, Bronwyn and Rose Marie Ham, 1999. The patent paradox revisited: determinants of patenting in the U.S. semiconductor industry 1980-94, UC Berkeley and NBER.

[23] Martinelli, Daniel. "Labour market entry and mobility of young French PhDs." Innovative People-Mobility of skilled personnel in national innovation systems. OECD Proceedings. 2001.

[24] Mangematin, Vincent. "Individual careers and collective research: is there a paradox?." International Journal of Technology Management 22.7-8: 670675.2001.

[25] Zucker, L.G., Darby, M., 1997. Individual action and the demand for institution: American Behavioral Scientist 4, 502-513.

[26] Griliches, Zvi and Haim Regev, Productivity and firm turnover in Israeli industry: 1979-1988: Journal of Econometrics 65, 175-203. 1995.
[27] Trajtenberg, Manuel, 1990. A penny for your quotes: patent citations and the value of innovations: The Rand Journal of Economics, 21(1), 172-187.

[28] Jaffe, Adam, Manuel Trajtenberg, and Michael Fogarty. The meaning of patent citations: reports on the NBER/Case-western reserve survey of patentee: NBER Working Paper No. 7631. 2000.

[29] Reitzig, Markus, 2003. What determines patent value? Insights from the semiconductor industry: Research Policy 32, 12-26.

[30] Hall, Bronwyn, Adam Jaffe and Manuel Trajtenberg., Market value and patent citations, RAND Journal of Economics 36, 16-38. 2005.

[31] Harhoff, Dietmar, et al. "Citation frequency and the value of patented inventions." Review of Economics and statistics 81.3: 511-515.1999.

[32] Hall, Bronwyn H., Adam B. Jaffe, and Manuel Trajtenberg. The NBER patent citation data file: Lessons, insights and methodological tools. No. w8498. National Bureau of Economic Research, 2001.

[33] Warren Boeker, Executive Migration and Strategic Change- The Effect of Top Manager Movement on Product: Administrative Science Quarterly: Johnson Graduate School of Management, Cornell University, Vol. 42, No. 2, 213-236. 1997.

[34] Zucker, Lynne G., and Michael R. Darby. "Star scientists and institutional transformation: Patterns of invention and innovation in the formation of the biotechnology industry." Proceedings of the National Academy of Sciences 93.23: 12709-12716.1996.

[35] Zellner, C., The Economic Effects of Basic Research: Evidence for Embodied Knowledge Transfer Via Scientists' Migration: Research Policy, 32,1881-1895. 2003.

[36] Borgatti, S. P. Centrality and network flow. Social networks, 27(1), 55-71. 2005.

[37] Amalya L Oliver, Scientific and Technical Human Capital: Research Policy, Volume 33, Issue 4, 583-597. 2004.

[38] Tsai, Wenpin. "Knowledge transfer in intraorganizational networks: Effects of network position and absorptive capacity on business unit innovation and performance." Academy of management journal 44.5: 996-1004.2001.

[39] Jaffe, Adam B., and Manuel Trajtenberg. Patents, citations, and innovations: A window on the knowledge economy. MIT press, 2002.

[40] Freeman, Linton C. "Centrality in social networks conceptual clarification." Social networks 1.3: 215-239.1978.

[41] Stefano Breschi, Christian Catalinia, 2010. Tracing the links between science and technology: An exploratory analysis of scientists' and inventors' networks: Research Policy, Volume 39, Issue 1, 14-26.

[42] Marsden, Peter V. "Egocentric and sociocentric measures of network centrality." Social networks 24.4: 407-422.2002

[43] Wehrli, Stefan. "Personality on social network sites: An application of the five factor model." Zurich: ETH Sociology (Working Paper No. 7) .2008.

[44] Scott, J. 2000. Social network analysis, SAGE express.

[45] Ibarra, H. 1992, Homophily and differential returns: Sex differences in network structure and access in an advertising firm: Administrative Science Quarterly, Vol. 37, No. 3,422-447.

[46] Yoon, Byungun, and Yongtae Park. "A text-mining-based patent network: Analytical tool for high-technology trend." The Journal of High Technology Management Research 15.1: 37-50.2004.

[47] Kuznets, Simon. "Inventive activity: problems of definition and measurement." The rate and direction of inventive activity: Economic and social factors. Princeton University Press, 19-52. 1962.

[48] Carpenter, Mark, Francis Narin and Patricia Woolf, Citation rates to technologically important patents: World Patent Information 3, 160163.1981 .

[49] Akira Goto, Kazuyuki Motohashi, Construction of a Japanese Patent Database and a first look at Japanese patenting activities: Research Policy Volume 36 Issue 9, 1431-1442. 2007.

[50] Hall, Bronwyn and Jacques Mairesse, Exploring the relationship between R\&D and productivity in French manufacturing firms: Journal of Econometrics 65(1), 263-293. 1995.

[51] Mairesse, Jacques and Bronwyn Hall. Estimating the productivity of research and development in French and United States manufacturing firms: NBER, 285-315.1996.

[52] Harhoff, Dietmar. "R\&D and productivity in German manufacturing firms." Economics of Innovation and New Technology 6.1: 29-50.1998.

[53] Ayano Fujiwara, "The Knowledge Spillover Resulting from the Mobility of Knowledge Workers" in 2017 6th International Conference on Industrial Technology and Management (ICITM), United Kingdom, 2017. 